\title{
Active Cytomegalovirus Retinitis after the Start of Antiretroviral Therapy
}

David Heiden, M.D.,1 NiNi Tun, M.B.B.S.,2 Frank N. Smithuis MD, PhD,3

Jeremy D. Keenan, MD. MPH,4 Catherine E. Oldenburg, ScD MPH,4

Gary N. Holland, M.D.,5 and W. Lawrence Drew, MD, PhD.6

1. Department of Ophthalmology, California Pacific Medical Center, San Francisco California, and Seva Foundation, Berkeley, California, USA.

2. Medical Action Myanmar, Yangon, Myanmar.

3. Myanmar Oxford Clinical Research Unit and Medical Action Myanmar, Yangon, Myanmar.

4. Francis I. Proctor Foundation and Department of Ophthalmology, University of California, San Francisco, California, USA.

5. Ocular Inflammatory Disease Center, UCLA Stein Eye Institute and Department of Ophthalmology, David Geffen School of Medicine at UCLA, Los Angeles, California, USA.

6. Departments of Laboratory Medicine and Medicine, UCSF and Mount Zion Medical Center, San Francisco, California, USA.

RUNNING TITLE: Active CMV Retinitis after ART

KEY WORDS: cytomegalovirus, CMV retinitis; treatment CMV retinitis; diagnosis CMV retinitis; AIDS-related opportunistic infections; eye examination in AIDS

FUNDING: This research received no specific grant from any funding agency in the public, commercial or not-for-profit sectors

DISCLOSURES: There are no conflicts of interest for any of the authors.

Summary: 73

Word count: 1854

Tables/illustrations: 1 Table; 1 Figure

References: 25

\section{ETHICS}

This study did not require ethical approval because it used retrospective de-identified data.

\author{
AUTHOR CONTRIBUTIONS \\ Developing research question: WLD, JDK, DH, GNH \\ Acquisition of data: DH, NNT, FS \\ Analysis of data: DH, NNT, JNH, CEO, GNH, WLD \\ Writing preliminary drafts: $\mathrm{DH}$ \\ Revising drafts: DH, WLD, JDK, GNH, CEO
}


Heiden. Active CMV Retinitis after ART. Page 2 of 9.

All authors significantly contributed to this manuscript and approve the final draft

CORRESPONDING AUTHOR: David Heiden M.D., 641 Clayton Street, SF, CA 94117;

cell phone 415-740-2265; E-mail: davidheiden@ gmail.com

\section{SUMMARY.}

Patients with AIDS-related cytomegalovirus (CMV) retinitis receiving combined antiretroviral therapy (cART), but not specific anti-CMV therapy, consistently showed active retinitis for several months. Delayed diagnosis and treatment of CMV retinitis may have severe consequences. Patients first entering care with advanced HIV infection and vulnerability to reactivation of latent CMV infection should be screened immediately for CMV retinitis by dilated indirect ophthalmoscopy, and treated with specific antiCMV therapy without delay, in addition to cART. 


\section{INTRODUCTION}

The introduction of combined antiretroviral therapy (cART) strikingly reduced the incidence of AIDS-related cytomegalovirus (CMV) retinitis in the United States and Western Europe (1), but the disease remains an important problem in many middle and low-income countries, particularly in resource-limited settings $(2,3)$.

Soon after cART became available there were anecdotal reports of active CMV retinitis resolving with cART alone (4). We suspect that these reports as well as the marked reduction of CMV retinitis that accompanied introduction of cART in highincome countries, has led to practice patterns in resource-limited settings that embrace an incomplete understanding of the anti-CMV benefits of cART.

The phenomenon of active CMV retinitis after start of cART is an important issue world-wide, because most HIV-infected individuals in middle and low-income countries are first diagnosed with CMV retinitis after start of cART, typically after substantial delay $(5,6)$ Lesion activity is a risk factor both for vision-threatening immune recovery uveitis (IRU) among people on cART and for retinal detachment. Moreover, as active lesions expand, they can threaten structures like the fovea and optic disc. Early diagnosis of active retinitis and treatment with anti-CMV drugs is therefore critical.

We found no studies on a computerized literature search that systematically investigated the relationship between duration of cART and CMV retinitis activity at diagnosis. In Myanmar, we had the opportunity to examine a group of patients with CMV retinitis who were being treated with cART but had never been treated with specific antiCMV therapy. With the continuing burden of CMV retinitis $(2,3,5,6)$ this historical dataset remains timely, and we undertook this study to improve clinical recognition of the relationship between CMV retinitis activity and CART, with the goal of encouraging better strategies for managing CMV retinitis. We describe a group of HIV patients whose CMV retinitis had not become inactive after several months of cART alone in the absence of specific anti-CMV therapy.

\section{METHODS}

We performed a retrospective, cross-sectional review of medical records from a consecutive series of patients with AIDS-related CMV retinitis who were examined at five HIV disease clinics administered by Medicins Sans Frontieres/Holland in Yangon, Myanmar in November 2006. An ophthalmologist (DH) experienced in the diagnosis of CMV retinitis had performed a single retinal examination with an indirect ophthalmoscope through a fully dilated pupil. All clinic patients with nadir CD4+ Tlymphocyte counts $<50$ cells/ml or visual symptoms underwent indirect ophthalmoscopy.

Visual acuity was assessed for each eye according to the following categories: counting fingers $(\mathrm{CF})$ at 3 meters, $\mathrm{CF}$ at 1 meter, hand motions $(\mathrm{HM})$, light perception (LP), and no light perception (NLP). CMV retinitis was classified as active versus inactive based on standard ophthalmoscopic features. Active retinitis was characterized by border opacification (whitening); inactive retinitis was characterized by flat chorioretinal scar with or without pigment or gliosis, and free of edematous or granular border opacification. The extent of retinitis was assessed by estimating the total retinal surface area. The presence of posterior pole involvement (i.e., zone 1), retinal detachment, and immune recovery uveitis were noted, with the latter defined as vitritis or 
posterior synechiae. After ophthalmic examination, the medical record was reviewed for information on cART status and duration over the previous 6 months. The cART regimen was stavudine plus lamivudine and nevirapine, and compliance was monitored as part of routine patient care. All patients with active retinitis were treated with weekly intraocular ganciclovir, $2.5 \mathrm{mg}$ in $0.05 \mathrm{ml}$ volume by standard sterile technique.

The relationship between retinitis activity and duration of cART among patients with CMV retinitis was assessed using penalized maximum likelihood logistic regression.

One year follow-up examination was attempted for the group of 19 patients with active CMV retinitis who were treated with intraocular ganciclovir.

\section{RESULTS}

Among 179 HIV patients who were examined by indirect ophthalmoscopy, 36 patients with CMV retinitis were currently on cART and had never received specific antiCMV therapy.

Of these 36 patients with CMV retinitis on cART, 19 had active CMV retinitis and 17 had inactive CMV retinitis. Among patients on cART 14 weeks or less, each of 16 had active retinitis. Figure 1 depicts the results of a single examination of each patient and provides the proportion of patients with active CMV retinitis stratified by increasing durations of cART. Patients with CMV retinitis who had been on shorter courses of cART were more likely to have active disease $(\mathrm{P}<0.001$, test for linear trend over the time categories displayed).

We compared the nadir CD4 count of all 19 patients with active CMV retinitis to $14 / 17$ patients with inactive CMV retinitis (data missing in 3 patients with inactive CMV retinitis) and found no statistical difference between those with active retinitis (mean 16.5, 95\%CI 9.7 to 23.2) and inactive retinitis (mean 19.7, 95\%CI 9.1 to 30.3. In 30/33 (91\%) of patients the CD4+ lymphocytes count was below 50 cells/ ul with a range of 4 66 cells/ul.

Bilateral retinitis was present in 9 of 19 (47\%) with active retinitis and 5 of 17 $(29 \%)$ with inactive retinitis, a non-statistically significant difference $(\mathrm{P}=0.32)$. The clinical features of examined eyes are shown in Table 1; there were no statistically significant differences between eyes with active and inactive CMV retinitis.

Table 1.

Clinical characteristics of eyes from a series of patients diagnosed with cytomegalovirus (CMV) retinitis who had not received prior anti-CMV treatment. All patients were under treatment with cART

\begin{tabular}{|c|c|c|c|c|c|}
\hline \multirow[b]{2}{*}{ Characteristic } & \multicolumn{2}{|c|}{ Active CMV retinitis } & \multicolumn{2}{|c|}{ Inactive CMV retinitis } & \multirow[b]{2}{*}{$\begin{array}{c}\mathrm{P}- \\
\text { value }\end{array}$} \\
\hline & $\mathrm{N}^{*}$ & $\begin{array}{c}\mathrm{N}(\%) \text { or mean } \pm \\
\mathrm{SD}\end{array}$ & $\mathrm{N}^{*}$ & $\begin{array}{l}\mathrm{N}(\%) \text { or mean } \pm \\
\mathrm{SD}\end{array}$ & \\
\hline Visual acuity & & & & & 0.30 \\
\hline CF 3m & 28 & $18(64 \%)$ & 22 & $12(55 \%)$ & \\
\hline $\mathrm{CF} 1 \mathrm{~m}$ & 28 & $1(4 \%)$ & 22 & $2(9 \%)$ & \\
\hline HM & 28 & $0(0 \%)$ & 22 & $1(5 \%)$ & \\
\hline LP & 28 & $4(14 \%)$ & 22 & $6(27 \%)$ & \\
\hline NLP & 28 & $5(18 \%)$ & 22 & $1(5 \%)$ & \\
\hline
\end{tabular}


Heiden. Active CMV Retinitis after ART. Page 5 of 9.

\begin{tabular}{lccccc} 
Percent of retinal surface area & 22 & $40 \% \pm 33 \%$ & 17 & $33 \% \pm 24 \%$ & 0.83 \\
Zone 1 involvement & 22 & $9(41 \%)$ & 17 & $6(35 \%)$ & 0.49 \\
Retinal detachment & 23 & $3 / 23$ & 17 & $5 / 17$ & 0.25 \\
$\quad$ Size of detachment & 3 & $81 \% \pm 29 \%$ & 5 & $92 \% \pm 14 \%$ & 0.61 \\
Immune recovery uveitis & 23 & $5(22 \%)$ & 19 & $4(21 \%)$ & 0.99 \\
\hline
\end{tabular}

*Eyes with available data

$\dagger$ Fisher's exact test for categorical variables and Wilcoxon rank sum test for continuous variables, ignoring correlation between two eyes of same patient

At one year we re-examined 9/19 (47\%) of patients who had active CMV retinitis and were treated with intraocular ganciclovir. Seven patients had been lost to follow-up and 3 patients had died. Among 9 patients provided with specific anti-CMV therapy 4 patients had bilateral retinitis giving a total of 13 eyes. Three eyes had LP or NLP vision on the prior initial examination. None of 10 eyes with intact vision on initial evaluation and who had been treated with specific anti-CMV therapy had become blind at one-year follow-up.

\section{DISCUSSION}

The observation of active retinal lesions in all patients with CMV retinitis who were receiving cART for 14 weeks or less confirms the need for early diagnosis and specific anti-CMV therapy, in addition to cART. Our clinical data also show an inverse relationship between disease activity and duration of cART, with most, but not all, patients on cART for 6 months demonstrating inactive retinitis. In order to identify patients who require specific anti-CMV therapy, thereby avoiding the potentially severe consequences of an unchecked and relentlessly progressive infectious disease (7), diagnostic eye examination must be performed on all vulnerable patients as soon as the patient first enters care.

In vitro studies suggest that functional immune reconstitution capable of control of CMV replication is distinct from the general recovery of the CD4 count. It is thought that control of CMV replication requires recovery of a specific subset of CD4 lymphocytes (8). In vivo, after a single month of cART, CD4 counts may exceed 100 cells/ul and HIV blood level may fall several log units, but CMV blood level is essentially unchanged (9). The mean time to clear CMV viremia on cART alone has been estimated as approximately 13.5 weeks (10). Thus, productive CMV infection will continue after initiation of cART until specific CMV immune reconstitution occurs. During this window of delayed reconstitution of anti-CMV immune capacity, new cases of CMV retinitis have been recognized, even in patients with CD4 > 200/ul (11). Our data and other evidence $(8,9,10,11)$ suggests that specific therapy for CMV infection must be continued until retinitis is inactive and until there has been enough time on cART for re-constitution of the capacity to contain CMV infection, typically 3-4 months. Also, surveillance of all vulnerable patients should be continued until there has been enough time for the occurrence of specific immune reconstitution to CMV.

The dramatic decline of AIDS-related CMV retinitis in high-income countries is attributable to widespread HIV screening and early initiation of cART, before the immune system becomes profoundly compromised. This desired approach has been well 
implemented in Western and Central Europe and North America, regions that account for only $7 \%$ of the total burden of HIV infected patients (12).

While there is also a definite decline in the proportion of HIV-infected patients first presenting for care with advanced immune deficiency in middle and low-income countries, up to $1 / 3$ still present with advanced disease (13). Success at reducing the proportion of patients who present with late disease in Southeast Asia has been frustrated by the stigma associated with a diagnosis of HIV infection, as well as stigmatization of groups at increase risk of HIV acquisition in concentrated epidemic settings (sex workers, people who use injecting drugs, men who have sex with men, and transgender individuals) (14).

Early screening and diagnosis of CMV retinitis is desirable health policy, yet only one middle or low-income country (Myanmar) attempts to offer an immediate eye examination as part of routine care for new patients with a CD4 count $<100$ cells $/ \mu 1(15)$. In Thailand and India, guidelines for patients with CD $4<100$ cells $/ \mu 1$ include an eye examination, but if an eye examination is performed it occurs months (5) or even years (6) after the patient is already on cART. In reality, an eye examination is typically only prompted by visual symptoms, but symptoms may be unrecognized until after irreversible damage occurs (16). Based on clinical experience in countries other than Myanmar, we believe that our data are generalizable for a substantial proportion of patients in resourcepoor settings of Southeast Asia, China, and Eastern Europe.

There is persuasive clinical (17) and autopsy (18) evidence that AIDS-related CMV retinitis is only one part of a systemic infection, and contributes to mortality in addition to causing blindness. The powerful correlation between CMV retinitis and early AIDS mortality has long been recognized, with or without cART. Until the late 1980s, in San Francisco, with strong supportive care and medical expertise, the median survival in patients with CMV retinitis was 4 months (19), and in resource-limited settings before availability of cART, survival after a diagnosis of CMV retinitis was measure in weeks (20). At this time perhaps $1 / 3$ of patients with CMV retinitis may die before this treatable opportunistic infection is diagnosed, and often before initiation of cART $(21,22)$. An oral medication, valganciclovir, is effective for both retinitis and systemic disease (23), and systemic regimens have been demonstrated to reduce all-cause mortality (24). We may have the opportunity to raise the standard of care for patients who develop CMV retinitis to closely approach the standard in high-income countries by taking two limited steps: by providing early diagnosis; and by providing systemic therapy with valganciclovir.

In conclusions, routine appropriate history and physical examination provides early screening for tuberculosis, cryptococcal meningitis, pneumocystis pneumonia, and penicilliosis, but appropriate physical examination is rarely provided for CMV retinitis. Moreover, a recent report of providing prophylaxis against multiple microbial pathogens to reduce mortality in patients with advanced HIV infection entirely ignores CMV (25). Until there is widespread effective early HIV diagnosis and treatment in resource-limited settings, eye examination should be performed routinely on all patients who are vulnerable to CMV retinitis at the time they first enter health care, just as screening is provided for other serious opportunistic infections. By neglecting to include an appropriate eye examination, the potential for use of a simple intervention (valganciclovir therapy) is forfeited. Patients with CMV retinitis must be appropriately treated with systemic anti-CMV therapy in addition to cART. 


\section{REFERENCES}

1. Mocroft A, Sabin CA, Youle M, Madge S, Tyrer M, Devereux H, Deayton J, Dykhoff A, Lipman MC, Phillips AN, Johnson MA. Changes in AIDS-defining illnesses in a London Clinic, 1987-1998. J Acquir Immune Defic Syndr. 1999 Aug 15;21(5):401-7. 2. Heiden D, Ford N, Wilson D, et al. Cytomegalovirus retinitis: the neglected disease of the AIDS pandemic. PLoS Med 2007; 4: e334.

3. Ford N, Shubber Z, Saranchuk P, et al. Burden of HIV-related CMV retinitis in resource-limited settings: a systematic review. Clin Infect Dis 2013; 57: 1351-61.

3. Pathanapitoon K, Ausayakhun S, Kunavisarut P, et al. Blindness and low vision in a tertiary ophthalmologic center in Thailand: the importance of cytomegalovirus retinitis. Retina 2007; 27: 635-40.

4. Reed JB, Schwab IR, Gordon J, Morse LS. Regression of cytomegalovirus retinitis associated with protease-inhibitor treatment in patients with AIDS. American journal of ophthalmology. Aug 1997;124(2):199-205.

5. Ausayakhun S, Keenan JD, Ausayakhun S, Jirawison C, Khouri CM, Skalet AH, Heiden D, Holland GN, Margolis TP. Clinical features of newly diagnosed cytomegalovirus retinitis in northern Thailand. American journal of ophthalmology 2012; 153(5):923-931.

6. Agarwal A, Singh R, Sharma A, GuptaV, Dogra MR. (2017) Ocular Manifestations in Patients with Human Immunodeficiency Virus Infection in the Pre-HAART Versus the HAART Era in the North Indian Population. Ocular Immunology and Inflammation, 25:3, 396-404.

7. Palestine AG, Rodrigues MM, Macher AM, Chan CC, Lane HC, et al. (1984) Ophthalmic involvement in acquired immunodeficiency syndrome. Ophthalmology 91: 1092-1099.

8. Komanduri KV, Feinberg J, Hutchins RK, Frame RD, Schmidt DK, Viswanathan MN, Lalezari JP, McCune JM. Loss of cytomegalovirus-specific CD4+ T cell responses in human immunodeficiency virus type 1-infected patients with high CD4+ T cell counts and recurrent retinitis. J Infect Dis. 2001 Apr 15;183(8):1285-9.

9. O'Sullivan C, Drew W, McMullen D, et al. Decrease of Cytomegalovirus replication in human immunodeficiency virus infected-patients after treatment with highly active antiretroviral therapy.J Infect Dis 1999; 180: 847-849.

10. Deayton JR, Mocroft A, Wilson P, Emery VC, Johnson MA, Griffiths PD. Loss of cytomegalovirus (CMV) viraemia following highly active antiretroviral therapy in the absence of specific anti-CMV therapy. AIDS:13(10):1203-6.

11. Jacobson MA, Zegans M, Pavan PR, O’Donnell JJ, Sattler F, Rao N, Owens S, Pollard R. (1997) Cytomegalovirus retinitis after initiation of highly active antiretroviral therapy. Lancet 349:1443-45.

12. World Bank and HIV/AIDS: The Facts. 2012. Fact sheet]. UNAID Fact Sheet

November 2016. Available from:

http://www.unaids.org/en/resources/presscentre/factsheets/

Accessed May 1, 2017. 
13. Ford N, Doherty M. The enduring challenge of advanced HIV infection. NEJM 2017; $377: 3 ; 283$.

14. Mukolo A, Villegas R, Aliyu M, Wallston KA. Predictors of late presentation for HIV diagnosis: a literature review and suggested way forward. AIDS Behav. 2013 Jan;17(1):5-30. doi:10.1007/s10461-011-0097-6.

15. Tun NN, London N, Kyaw MK, Smithuis F, Ford N, Margolis T, Drew WL, Lewallen S, Heiden D. CMV retinitis screening and treatment in a resource-poor setting: three-year experience from a primary care HIV/AIDS programme in Myanmar. Journal of the International AIDS Society 08/2011; 14:41

16. Liu Y, Chen AS, Kamphaengkham S, Leenasirimakul P, Jirawison C, Ausayakhun S, Margolis TP, Keenan JD. Diagnostic Utility of Ocular Symptoms and Vision for Cytomegalovirus Retinitis. PLoS One. 2016 Oct 27;11(10):e0165564. doi:

10.1371/journal.pone.0165564. eCollection 2016. PMID: 27788232

17. Yust I, Fox Z, Burke M, et al. Retinal and extra ocular cytomegalovirus end-organ disease in HIV-infected patients in Europe: a EuroSIDA study, 1994-2001. Eur J Clin Microbiol Infect Dis 2004; 23:550-59.

18. Brantsaeter AB, Liestel K, Goplen AK, Dunlop O, Bruun JN. CMV disease in AIDS patients: incidence of CMV disease and relation to survival in a population-based study from Oslo. Scand J Infect Dis 2002; 34:50-5.

19. Harb GE, Bacchetti P, Jacobson MA. Survival of patients with AIDS and cytomegalovirus disease treated with ganciclovir or foscarnet. AIDS, 1991. 5(8):959-65. 20. Balo KP, Amoussou YP, Bechetoille A, Mihluedo H, Djagnikpo PA, et al. (1999) [Cytomegalovirus retinitis and ocular complications in AIDS patients in Togo]. $\mathrm{J}$ Fr Ophthalmol 22: 1042-1046.

21. Tun NN, Smithuis F, London N, Drew WL, Heiden D. Mortality in patients with AIDS-related cytomegalovirus retinitis in Yangon, Clin Infect Dis. 2014 Dec 1;59(11):1650-1.

22. Shi Y, Lu H, He T, Yang Y, Liu L, et al: Prevalence and Clinical Management of Cytomegalovirus Retinitis in AIDS patients in Shanghai, China. BMC Infect Dis. 2011 Nov 24;11:326.

23. Martin DF, Sierra-Madero J, Walmsley S, et al. A controlled trial of valganciclovir as induction therapy for cytomegalovirus retinitis. N Engl J Med. 2002;346:1119-1126. 24. Jabs DA Ahuja A, MS, Van Natta M, J. P. Dunn JP, Steven Yeh S, for the Studies of the Ocular Complications of AIDS Research Group. Comparison of Treatment Regimens for Cytomegalovirus Retinitis in Patients with AIDS in the Era of Highly Active Antiretroviral Therapy Ophthalmology 2013;120:1262-1270.

25. Hakim J, Musiime V, Szubert AJ, et al. Enhanced prophylaxis plus antiretroviral therapy for advance HIV infection in Africa. N Engl J Med 2017;377;233-45.

Figure 1. The proportion of patients with active CMV retinitis stratified by increasing durations of cART. 


\section{FIGURE LEGEND}

The relationship between cytomegalovirus (CMV) retinitis activity and duration of combined antiretroviral therapy (cART) is provided for a total of 36 patients with CMV retinitis who were stratified into 8 week periods of cART duration; the percentage of patients in each stratum who were found to have active CMV retinitis on a single examination is shown in the black bar.

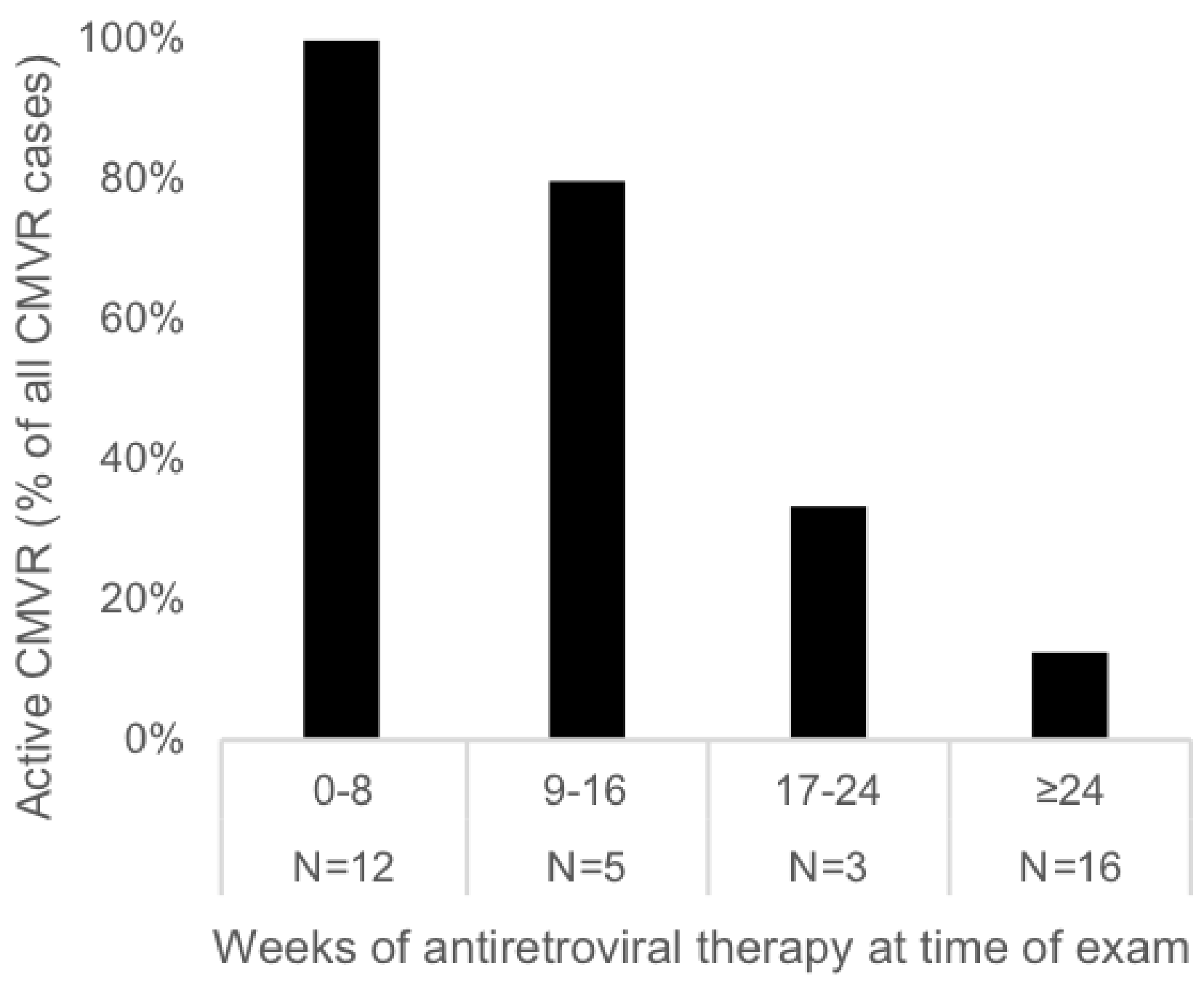

